\title{
A docência na Educação Superior e as didáticas especiais: campos em construção
}

IIma Passos Alencastro Veiga*

\section{Resumo}

O presente estudo visa discutir a docência na Educação Superior sob duas óticas. A primeira apresenta uma perspectiva com produções diversas, relativas aos processos de mudanças legais e de reforma educacional, bem como 0 exame dessas interferências na constituição da docência na Educação Superior, sob a ótica da racionalidade técnica . A segunda perspectiva refere-se à caracterização da docência e à constituição das didáticas específicas, abrangendo o estudo da aula e a problemática das disciplinas acadêmicas que supõem uma configuração conceitual e metodológica, com ênfase na natureza e especificidade do campo científico, nas orientações da didática geral, nas experiências acumuladas e suas relações com o contexto social. Discutir a docência na Educação Superior na contemporaneidade, com as transformações políticas e educacionais, implica repensar alguns fundamentos sob os quais ela se organiza. Trata-se de um campo que se está configurando a partir dos estudos e pesquisa sobre a docência e as aulas na Educação Superior.

Palavras-chave: Educação Superior, docência, didáticas especiais.

\section{The teaching in the high education and the special didactics: fielding in building}

\section{Abstract}

The present study aims to discuss the teaching in higher education under two perspectives. The first presents a perspective with several productions, concerning the processes of legal changes and the educational reform, as well as the examination of those interferences in the constitution of the teaching in higher education, under the technical rationality point of view. The second perspective concerns the characterization of teaching and the constitution of the specific didactics, comprising the study of lectures and the issue of the academic courses that assume a conceptual and methodological configuration with emphasis on the nature and specificity in the scientific field; in the orientations of general didactic; in the accumulated experiences and its relationship with the social context. To discuss teaching in higher education in the contemporaneity the

\footnotetext{
* Professora Doutora da Universidade de Brasília (UnB), Brasília, Distrito Federal, Brasil.
} 
political and educational transformations imply rethinking some grounds under which it is organizes. It is a field which is being configured from the studies and research about the teaching and the lectures within higher education.

Keywords: high education, teaching, special didactics.

\section{Introdução}

A estruturação do campo da docência na Educação Superior é muito recente e deu-se efetivamente, na década de 1990, com a implantação dos processos avaliativos e, mais especificamente, da avaliação do corpo docente pelo discente, bem como a presença das tecnologias da informação e comunicação. Trata-se atualmente de um campo intelectual em construção, subdividido em duas grandes tendências.

A primeira apresenta uma perspectiva com produções diversas aos processos de mudanças legais e de reforma educacional, bem como ao exame dessas interferências na constituição da docência na Educação Superior, sob a ótica da racionalidade técnica.

A segunda refere-se à caracterização da docência e à constituição de didáticas específicas, abrangendo o estudo da aula e a problemática das disciplinas acadêmicas que supõem uma configuração conceitual e metodológica, com ênfase na natureza e especificidade do campo científico, nas orientações didáticas gerais, nas experiências acumuladas e suas relações com o contexto social.

Busco, neste artigo, discutir a docência na Educação Superior sob a ótica das duas perspectivas. Assim, tratar a docência na Educação Superior, na contemporaneidade, com as transformações políticas e educacionais, implica repensar alguns fundamentos sob os quais se organiza a docência.

\section{Fundamentos que embasam a docência na perspectiva da racionalidade}

A docência na Educação Superior foi influenciada pela concepção disciplinar e fragmentada que separa a teoria da prática, o saber do fazer, o sujeito do objeto. Dessa forma, a docência não aborda a complexidade do processo didático em seus pilares: ensinar, aprender, pesquisar e avaliar. Isso leva os professores a uma dependência do conhecimento do campo científico para a condução de sua prática docente, o que contribui para a caracterização da docência calcada na transmissão do conhecimento existente. Assim, a docência na Educação Superior continua a ter como exigência a competência científica, deixando de lado a competência pedagógico-didática. A conexão entre instituição de Educação Superior, conhecimento pedagógico e experiencial foi banida da concepção de docência. 
A docência na Educação Superior e as didáticas especiais: campos em construção

A docência fundamentada no fazer, concebida para atingir o caráter prático, não contempla a apreensão do trabalho docente nem as possibilidades de redimensionar a teoria do campo científico com outras áreas do conhecimento, tais como: os pedagógicos, os experienciais, entre outros. Vale ressaltar que essas limitações são decorrentes de uma concepção de docência segundo a racionalidade técnica em que

[...] a atividade do profissional é, sobretudo, instrumental, dirigida para a solução de problemas mediante a aplicação rigorosa de teorias-técnicas científicas. Para serem eficazes, os profissionais da área das ciências sociais devem enfrentar os problemas concretos que encontram na prática, aplicando princípios gerais e conhecimentos científicos derivados da investigação. (GÓMEZ, 1992, p. 96)

A docência na Educação Superior sustentada na racionalidade instrumental é eminentemente técnica, com ausência de articulação entre diferentes conhecimentos que permeiam a aula. Orientada na concepção epistemológica fundamentada na racionalidade técnica, supõe duas formas de conhecimentos: as disciplinas formais da lógica e da matemática, e as ciências empíricas de acordo com o modelo mecanicista de ciências naturais (SANTOS, 1987). Sob esse fundamento, o conhecimento científico específico é mais valorizado e tem maior prestígio que o conhecimento pedagógico, na formação de profissionais. A ideia é de que quem tem conhecimento específico sabe ensinar.

Para Imbernón (1998), a racionalidade técnica prioriza a cultura técnica e científica em detrimento da cultura humanista e artística, privilegiada pela orientação acadêmica. A formação é concebida como uma proposta de transmissão acadêmica de conhecimentos vinculados aos estudos das disciplinas curriculares, tendo como finalidade a recuperação da tradição clássica na educação, valorizando o estudo de grandes autores e de suas obras. Ao professor, nessa concepção, caberia a transmissão dos conteúdos culturais. Para o autor, "[...] a formação instrumental, prestando maior atenção às demandas imediatas do mercado do que às necessidades menos imediatas, porém mais sólidas, de uma cultura mais completa, global e integral” (IMBERNÓN, 1998, p. 38).

Sob essa perspectiva, o conhecimento pedagógico ficou distante da Educação Superior, fortalecendo a ideia de que o importante é o domínio do conhecimento da área específica e das metodologias de pesquisa para sua produção.

\section{O que pensam os autores sobre a docência na Educação Superior}

Cada autor, ao compreender a docência na Educação Superior e analisar suas características, apresenta um conjunto de elementos expressivos para sua constituição. 


\section{IIma Passos Alencastro Veiga}

Para Benedito, Ferrer e Ferreres (1995), a docência deve ser comprometida com a ideia de potencializar a aprendizagem dos estudantes, com o fortalecimento do conhecimento construído nas aulas e nos diferentes espaços educativos e que seja relevante para a formação profissional e que contribua com a melhoria da sociedade. Os autores enfatizam ainda a preocupação com o preparo dos estudantes para a construção da autonomia, da interpretação crítica do conhecimento e da sociedade.

Garcia (1999) evidencia que, de forma geral, na tentativa de delimitar um perfil desejável de docência, considera as seguintes dimensões: cognitiva (níveis de pensamento promovidos nos estudantes), socioemocional (elogios, críticas, iniciação, resposta), substantiva (conteúdo das aulas) e comunicativa (linguagem, clareza, fluidez, expressividade). $O$ autor acrescenta que, além dos conhecimentos do campo específico, a docência envolve habilidades de avaliação, resolução de conflitos, análise do contexto, como também a compreensão, em face da diversidade cultural, dos aspectos do currículo oculto e do currículo em ação.

Zabalza (2004) apresenta três grandes dimensões na definição do papel docente sinteticamente apresentadas a seguir:

a) dimensão profissional que envolve os componentes essenciais que definem uma profissão: suas exigências, construção da identidade profissional, principais dilemas, necessidade de formação inicial e permanente, etc.;

b) dimensão pessoal que considera alguns aspectos importantes da docência: tipo de envolvimento e compromisso pessoal característico da profissão, ciclos de vida e situações pessoais que afetam os professores, problemas de ordem pessoal, fontes de satisfação e insatisfação no trabalho;

c) dimensão administrativa relacionada aos aspectos contratuais, com os sistemas de seleção e formação, com os incentivos, com as condições e regime de trabalho. Essas dimensões não são excludentes, e alguns dos aspectos que são tratados no bojo de uma dimensão poderiam ser trabalhados sob outra. Dito em termos simples, as dimensões são intercomplementares.

Na perspectiva dos autores citados, é possível identificar na docência da Educação Superior o papel de uma ação cultural, as dimensões e a ampliação de trabalho. Os professores são chamados a ministrar aulas nos cursos de graduação e de pós-graduação, realizar pesquisas, orientar trabalhos de conclusão de curso e iniciação científica, monografias, dissertação e teses, responder às exigências gerenciais como coordenação de cursos, direção de entidades acadêmicas, comissões, bancas examinadoras, pressão pela produção teórico-científica, etc. Essas demandas são divergentes e o professor se encontra num emaranhado de tarefas. Assim, esse conjunto de funções ultrapassa o exercício da docência. 
A docência na Educação Superior e as didáticas especiais: campos em construção

Como atividade especializada, a docência tem os conhecimentos e exige do professor habilidades a fim de poder desempenhar adequadamente suas funções. Cada autor, ao tratar da concepção de docência, apresenta um conjunto de características que deveriam ser consideradas no processo de desenvolvimento profissional. Toda essa configuração apresentada pelos autores indica - em síntese - o perfil do docente da Educação Superior: ter conhecimento dos estudantes, da disciplina, do ensino de forma geral, da didática específica, do contexto histórico-político e conhecimentos experienciais. Os autores reconhecem que, apesar da ampliação do trabalho docente, é a dimensão formativa da Educação Superior que a docência deverá priorizar.

Assim, as características necessárias ao exercício da docência na Educação Superior extrapolam os limites do conhecimento aprofundado da disciplina de seu campo científico e a aquisição de habilidades complexas necessárias à condução do ensino.

\section{Um olhar sobre as didáticas especiais}

As didáticas na Educação Superior são disciplinas específicas ou especiais dentro do campo da didática de cunho geral, no campo epistemológico de cada disciplina, bem como na experiência acumulada pelos professores. $\mathrm{Na}$ teoria e na prática, as didáticas especiais na Educação Superior procuram um espaço de conhecimento orientado para a compreensão do processo didático que ocorre na aula, com base nas conexões com a realidade social e com as intencionalidades da formação de profissionais. Trata-se de um campo que se está configurando a partir dos estudos e pesquisas sobre a docência e as aulas na Educação Superior.

Pensar as diferentes didáticas especiais significa entendê-las sob a ótica de alguns autores e a partir de aulas observadas, com o intuito de ressaltar os pontos relevantes na tentativa de fortalecer as características das diferentes didáticas e suas conexões com as epistemologias das disciplinas, a concepção mais geral do ensino e a experiência dos professores.

Como todo estudo, as didáticas especiais adquirem seu significado na perspectiva teórica e prática em que se inscrevem. As didáticas especiais na Educação Superior têm sido objeto de estudos e nos posicionamentos teóricos em processo de construção.

Para Bedoya (2005), a didática especial é denominada assim porque deve corresponder a cada ciência ou disciplina específica, objeto de um determinado ensino. Isso supõe que toda ciência ou disciplina teriam implícitas estratégias didáticas ao lado das científicas ou investigativas para serem concretizadas em aula. Há uma identificação da didática com o conhecimento específico. O autor afirma que 


\begin{abstract}
A didática das disciplinas exige ou implica em um processo incessante de investigação e discussão replanejamento e construção constantes porque os problemas, para serem postos em prática, não como uma mera montagem instrumental e operativa, exigem a confrontação epistemológica e interdisciplinar. (BEDOYA, 2005, p. 181)
\end{abstract}

Por essa ótica, a didática especial não constitui um conjunto de rotinas predefinidas, pois o processo didático na sala de aula reproduze, ao mesmo tempo, constrói novos espaços. É uma didática que reinventa a prática pedagógica por intermédio da crítica do objeto estudado, isto é, o ensino no contexto da Educação Superior e do posicionamento político que direciona a ação do professor e dos alunos.

Libâneo (2008) busca a unidade entre uma didática geral do ensino e as metodologias específicas. Defende a unidade e a interdependência por meio da relação indissociável entre "as questões pedagógico-didáticas e a questão epistemológica" (p. 63). Sob essa ótica, o pedagógico está sempre em conexão com o epistemológico.

O autor discute quatro argumentos a favor da integração entre didática e didáticas específicas ou especiais sinteticamente apresentados a seguir:

a) a didática e as didáticas especiais têm o ensino como objeto de estudo e de pesquisa. Elas têm as mesmas tarefas, ou seja, explicitar o processo docente do conhecimento;

b) as formas de ensinar dependem das formas de aprender, pois o elemento nuclear é a aprendizagem do aluno;

c) aprender é desenvolver capacidades cognitivas do estudante de modo que dominem conceitos, formem esquemas mentais, raciocinem logicamente, argumentem e solucionem problemas, etc.;

d) a didática e as didáticas especiais, vinculadas à pedagogia, atribuem uma intencionalidade formativa ao ato de ensinar.

Nesse sentido, a didática e as didáticas específicas são interdependentes, uma vez que o objeto de estudo de ambas é o ensino.

A aula na educação superior e as possibilidades de construção de didáticas especiais ou específicas

A aula deve assinalar um sentido ao ensino planejado, desenvolvido e avaliado, edificando-o em torno da aprendizagem dos estudantes. É dinamizada pela relação pedagógica de cunho dialógico porque "registra em situação con- 
A docência na Educação Superior e as didáticas especiais: campos em construção

creta a maneira de viver essa relação como vínculo libertador que propicia o exercício da autonomia" (VEIGA et al, 2000, p. 176).

A aula é espaço de múltiplas relações e interações. Os alunos conseguem interagir entre si, aprendem a ensinar uns com os outros, desenvolvem um grau maior de autonomia. O professor interage com os alunos e com seus pares. É ainda durante a aula que o professor e alunos criam e recriam o processo didático: tomam decisões quanto à concepção, execução, avaliação do processo didático, quanto ao ensino, aprendizagem, pesquisa e avaliação, Veiga et al (2000, p. 175) afirmam que a aula "é o espaço onde o professor faz o que sabe, expressa o que sente e se posiciona quanto à concepção de sociedade, de homem, de educação, de escola, de aluno e de seu próprio papel".

A aula é um espaço e tempo revelador de intencionalidade, carregada de experiências e relação pedagógica e pode contribuir para a configuração da didática especial. Realiza-se em um espaço e em um tempo demarcado. É variada, sendo a mais comum aquela que ocorre entre quatro paredes. No entanto, há os espaços não-convencionais, tais como: os laboratórios, as quadras, os anfiteatros, os canteiros de obras, os hospitais, os postos e ambulatórios de saúde, as clínicas odontológicas, as plantações agrícolas, ou mesmo ao ar livre, em espaços sem demarcações.

A aula é um projeto de construção colaborativa que se configura planejadamente, bem como se explicita operacionalmente em torno de seus elementos constitutivos: objetivos, conteúdos, métodos e técnicas de ensino, tecnologias e avaliação. São elementos inter-relacionados em função da própria aula, que envolve o pensar a docência, e o agir também implica desvelar o novo e enfrentar o imprevisto. É, então, dinamizada pela relação pedagógica e, como vínculo libertador, propicia o exercício da autonomia. Enfim, a aula é espaço e tempo de formação humana e produção cultural.

Entendo que o estudo da aula implica a análise de diferentes pesquisas que indicam princípios orientadores com o objetivo de gerar reflexões sobre a didática e suas relações com as didáticas especiais. Uma variedade de explicações que os docentes colocam no decorrer da aula é produto de seu conhecimento do campo científico com o qual trabalham, do conhecimento sobre ensino e de sua experiência como docentes e nos vínculos que estabelecem em aula com as práticas profissionais.

As características das didáticas especiais foram construídas no decorrer de aulas observadas. A seguir, apresento - com base nas observações uma série de princípios e dimensões que caracterizam as didáticas especiais nas aulas da Educação Superior.

Ao analisar as narrativas da aula no curso de Medicina, o médicoprofessor deixou claro três princípios fundamentais: 


\section{IIma Passos Alencastro Veiga}

a) uma concepção de conhecimento médico que tem a prática como elemento de partida e estabelece relações entre a realidade do ambulatório de saúde e a fundamentação teórica, ressaltando a preocupação com a unicidade entre teoria e prática. O aluno deixa de ser um receptáculo passivo e passa a ter uma atitude reflexiva diante do conhecimento;

b) a articulação entre ensino e trabalho favorece a socialização do conhecimento mais concreto. Ao trabalhar com os estudantes problematizando as situações de saúde, analisando os prontuários dos pacientes, definindo soluções, compreendendo as questões levantadas, professor e estudantes estarão construindo conhecimento em torno de temas concretos, no sentido de desencadear ações preventivas e terapêuticas de saúde;

c) outro princípio importante está voltado para a formação do médico apto a realizar ações de promoção e recuperação da saúde, em nível individual e comunitário. A formação profissional propicia uma imersão intensa do estudante em atividades de assistência à saúde.

Trata-se de um processo de ensino instaurado por meio de uma didática especial assentada nas características fundantes do próprio campo da ciência médica, na relação pedagógica como vínculo libertador, nas relações teoria e prática, ensino e trabalho médico.

A segunda aula que sintetizo, como exemplo, para entender a caracterização da didática especial é a da diversidade e emancipação em que o professor de Informática procura construir o movimento da singularidade, no qual reconhece os estudantes como sujeitos coletivos e políticos. O professor estabeleceu as bases da relação pedagógica em aula, na medida em que não se prendeu apenas ao conteúdo do campo científico. A unicidade de ensinar, aprender, pesquisar e avaliar, dimensões do processo didático, está caracterizada pela relação dialógica do papel orientador e mediador do professor e a autoatividade do estudante. A didática especial construída pelo professor e seus alunos não é uma simples realização de atividades transmissivas: dá prioridade à assimilação e à produção do conhecimento, articula o conhecimento prático com as questões e traz o enfoque crítico para enriquecer as discussões. $\mathrm{A}$ concepção de aprender se altera, pois passa a ser concebida como um processo de descobrimento e de investigação.

A terceira aula observada foi no curso de Engenharia Agrícola, disciplina Mecanismos. A narrativa da aula observada evidenciou uma didática especial construída na esteira das seguintes características:

a) compromisso em querer mudar o processo de formação do engenheiro agrícola, no sentido de transformar o distante em próximo, contribuindo para a revisão do papel do aluno ao longo do curso. Redução das aulas expositivas e, no lugar delas, a proposta de elaboração, execução e avaliação de projetos 
A docência na Educação Superior e as didáticas especiais: campos em construção

em torno de galerias temáticas em que os conhecimentos avançam ao encontro uns dos outros. O projeto é interdisciplinar;

b) construção do conhecimento mediante a aprendizagem do aluno. Houve uma relação entre sujeito (estudante em atividade) e objeto dos conhecimentos (científicos, didáticos, experienciais), sob a orientação do professor, que mediou a atividade do sujeito diante do objeto para que o aluno pudesse construir seu conhecimento.

A didática especial desenvolvida pelo professor-engenheiro agrícola é resultante de uma trilogia: experiência na profissão de engenheiro agrícola, experiência na profissão docente e domínio do campo científico (epistemológico), conhecimento pedagógico e articulação com o contexto social.

Nas três aulas observadas com o objetivo de ressaltar as didáticas especiais, fui reconhecendo os princípios e as estratégias desenvolvidas pelos professores. As didáticas especiais desenvolveram-se na prática pedagógica dos docentes, tendo por base a epistemologia no campo científico de estruturação do curso, nos conhecimentos das experiências e nos conhecimentos didáticos mais gerais. As didáticas especiais identificam-se com o conhecimento do campo específico, pois implicam integrar o epistemológico com o pedagógico.

\section{E para concluir}

A docência na Educação Superior requer conhecimentos específicos, didáticos, experienciais e contextuais. A docência é, portanto, uma atividade profissional complexa, pois requer conhecimentos diversificados.

No âmbito da Educação Superior, a docência desempenha funções formativas e investigativas. Isso quer dizer que a docência deve estar a serviço de quem aprende e, ao fazê-lo, simultaneamente estará a serviço de quem ensina, pesquisa e avalia. Os dois, professor e estudantes, serão os beneficiados diretos da ação didático-pedagógica.

Convém ressaltar mais uma vez que não há separação entre campos da didática e das didáticas especiais ou específicas. Elas são interdependentes e complementares, pois o objeto de estudo de ambas é o ensino. Têm conteúdos próprios e objetivos voltados para a aprendizagem significativa dos estudantes. Portanto, é preciso reforçar as relações entre epistemologia e pedagogia.

A organização pedagógico-didática das aulas observadas evidenciou que os professores conduziram o ensino de forma eficaz ao iniciarem o estudo do tema da aula pelas situações concretas, estimulando os estudantes a estabelecerem relações entre conceitos e princípios, e criando novas situações de aprendizagem em níveis de complexidade crescente. 
Dessa forma, os três professores de Educação Superior procuraram integrar os conhecimentos do campo científico com os conhecimentos didáticos e investigativos da ciência ensinada, e os experienciais e contextuais. Nestes termos, as didáticas especiais ou específicas aparecem como elemento fundamental na articulação de sentido entre as dimensões individual e coletiva da docência na Educação Superior.

\section{Referências}

BEDOYA, J. I. Epistemología y Pedagogía: Ensayo histórico crítico sobre objeto y método pedagógicos. 6. ed. Bogotá: Eco Ediciones, 2005.

BENEDITO, A. V.; FERRER, V.; FERRERES, V. La formación universitaria a debate. Barcelona: Publicaciones Universitat de Barcelona, 1995.

GARCIA, C. M. Formação de professor: Para uma mudança educativa. Porto, 1999.

GÓMEZ, P. A. O pensamento prático do professor: A formação do professor como profissional reflexivo. In: NÓVOA, A.(Coord.). Os professores e sua formação. Porto: Dom Quixote, 1992.

IMBERNÓN, F. La formación y el desarrollo profesional del profesorado: hacia una nueva cultura profesional. 3. ed. Barcelona: Graó, 1998.

LIBÂNEO, J. C. Didática e epistemologia: para além do debate entre a didática e as didáticas específicas. In: VEIGA, I. P. A.; D’AVILA, C. M. (Orgs.). Profissão docente: Novos sentidos, novas perspectivas. Campinas: Papirus, 2008.

SANTOMÉ, J. S. Globalização e interdisciplinaridade: o currículo integrado. Porto Alegre: Artes Médicas, 1998.

SANTOS, B. S. Um discurso sobre as ciências. 7. ed. Porto: Afrontamento, 1987.

VEIGA, I. P. A. et al. A aula universitária e inovação. In: VEIGA, I. P. A.; CASTA$\mathrm{NHO}$, M. E. L. M. (Orgs.). Pedagogia universitária: a aula em foco. Campinas: Papirus, 2000.

ZABALZA, M. A. 0 ensino universitário: seu cenário e seus protagonistas. Porto Alegre: Artmed, 2004.

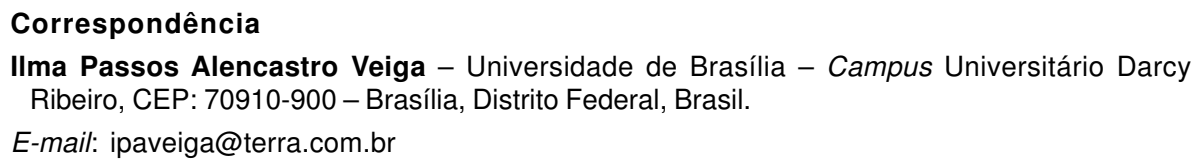

